\title{
INHIBICIÓN DEL TRÁNSITO INTESTINAL POR EL EXTRACTO METANÓLICO DE LAS HOJAS DE Annona muricata L (GUANÁBANA) EN RATONES
}

\author{
Inhibition of intestinal transit by methanolic extracts of Annona muricata L. sheets (Soursop) in mice \\ Dorka I Salinas $\mathrm{A}^{1}$, Juan C Araujo $\mathrm{G}^{2}$, César B Cisneros $\mathrm{H}^{3}$, César A Villena $\mathrm{N}^{4}$, Dennis A Senosain $\mathrm{T}^{5}$, Cecilia V Huarcaya $\mathrm{M}^{6}$, Jorge \\ L Arroyo A $\mathrm{A}^{7,8}$ \\ ${ }^{1}$ Centro Nacional de Control de Calidad, Instituto Nacional de Salud. Departamento de Fisicoquímica. ${ }^{2}$ Dirección de Autorizaciones \\ Sanitarias, Dirección General de Medicamentos, Insumos y Drogas. ${ }^{3}$ Farmacología de la Facultad de Medicina Humana, Universidad \\ San Pedro, Chimbote. ${ }^{4}$ Laboratorio Instituto Quimioterápico. ${ }^{5}$ Dirección de Salud, Ministerio de Salud. ${ }^{6}$ Departamento de Farmacia, \\ Hospital Nacional Santa Rosa. ${ }^{7}$ Instituto de Investigaciones Clínicas, Facultad de Medicina, Universidad Nacional Mayor de San Marcos. ${ }^{8}$ \\ Departamento de Farmacología de la Facultad de Medicina, Universidad Nacional Mayor de San Marcos.
}

\section{RESUMEN}

Las hojas de Annona muricata L. (guanábana) son empleadas tradicionalmente para tratar la diarrea aguda; al respecto, no se ha encontrado información que valide su propiedad antidiarreica, por lo que se propuso evaluar experimentalmente dicha acción y su toxicidad aguda. Para esto se conformaron aleatoriamente 11 grupos, de 6 ratones machos Balb-C 56 cada uno. El grupo uno sirvió de control (1 mL solución salina), los grupos experimentales 2, 3, 4, 5, 6 y 7 recibieron extracto metanólico de Annona muricata L. en dosis de 10, 25, 50, 75, 100 y $200 \mathrm{mg} / \mathrm{kg}$ de peso corporal, respectivamente; el grupo ocho recibió loperamida $1 \mathrm{mg} / \mathrm{kg}$ y el grupo nueve aceite de ricino $10 \mathrm{~mL} / \mathrm{kg}$. Se empleó carbón activado como marcador del tránsito intestinal según el modelo in vivo en ratones. La dosis letal 50 para la muestra biológica fue $229 \mathrm{mg} / \mathrm{Kg}$, con intervalo de confianza de $95 \%$ (límite superior 244,3 e inferior 220,9). Con dosis de $25 \mathrm{mg} / \mathrm{kg}$ del extracto de Annona muricata L. se observó una reducción del tránsito intestinal de 13,94\% (p<0,05), similar al dado por loperamida (13,36\%). Se concluye que, en condiciones experimentales, el extracto metanólico de las hojas de Annona muricata L. inhibió el tránsito intestinal.

Palabras clave: antidiarreico, Annona muricata L., carbón activado.

\section{SUMMARY}

The leaves of soursop (Annona muricata L.) are traditionally used to treat acute diarrhea; the matter, has not found enough information to validate its property antidiarrheal, so was proposed to assess experimentally the action and acute toxicity. For that, 11 groups were formed randomly, 6 male mice Balb-C 56 each. Group one served as control ( 1 mL saline), the experimental groups 2, 3, 4, 5, 6 and 7 received methanol extract of Annona muricata L. in doses: 10, 25, 50, 75, 100 and 200 mg/kg body weight, respectively; the group eight received loperamide $1 \mathrm{mg} / \mathrm{kg}$ and the group nine castor oil $10 \mathrm{~mL} / \mathrm{kg}$. Activated carbon was used as a marker of intestinal transit by model in vivo in mice. The lethal dose 50 for the biological sample was $229 \mathrm{mg} / \mathrm{kg}$, with a confidence interval of 95\% (244,3 upper and lower 220,9). At doses of $25 \mathrm{mg} / \mathrm{kg}$ of Annona muricata L., a reduction of intestinal transit of $13,94 \%(\mathrm{p}<0,05)$, similar to that given by loperamide $(13,36 \%)$. We conclude that in experimental conditions the methanol extract of leaves of Annona muricata L. inhibited the intestinal transit.

Keywords: antidiarrhoeal, Annona muricata L, activated charcoal.

\section{INTRODUCCIÓN}

A nivel mundial las enfermedades diarreicas son consideradas como una de las principales causas de morbilidad, con tasas que van desde 2 a 12 o más padecimientos por persona al año, los cuales representan un estimado de 12600 muertes de niños por día en Asia, África y América Latina ${ }^{(1)}$.

La diarrea es una consecuencia de la alteración en el transporte de agua y sus electrolitos a nivel del intestino, dando como resultado un aumento en el volumen del agua neta desde la mucosa intestinal hasta el lumen, que se traduce en los siguientes síntomas: mayor frecuencia de evacuación, incremento del volumen de agua y mayor volumen de las heces ${ }^{(2)}$. Todo esto propicia riesgos como: deshidratación y trastornos del equilibrio hidroelectrolítico (3). La alteración de la mucosa gastrointestinal, producto de un proceso inflamatorio subyacente, altera la permeabilidad y aumenta su motilidad ${ }^{(4)}$.
La Organización Mundial de la Salud (OMS) recomienda tratar la diarrea simple, en todas las edades, empleando medidas higiénico-dietéticas y sales de rehidratación oral, así como abstenerse de administrar cualquier otro medicamento por ser de eficacia dudosa o no demostrada y por el importante número y gravedad de efectos indeseables que pueden frecuentemente producir una relación riesgo/beneficio desfavorable ${ }^{(5)}$.

El tratamiento racional de la diarrea infecciosa requiere del uso altamente selectivo de pruebas de laboratorio para determinar los agentes etiológicos ${ }^{(6)}$.

Se han detectado y descrito varias sustancias endógenas relacionadas en el proceso desencadenante de la diarrea, las cuales incluyen la sustancia $\mathrm{P}$, acetilcolina, taquininas NK1 y NK2, y mediadores como VIP y PAF ${ }^{(7)}$.

En nuestro país la demanda asistencial contra esta patología nos exhorta a disponer de algún recurso terapéutico que ralentice la alteración en el transporte 


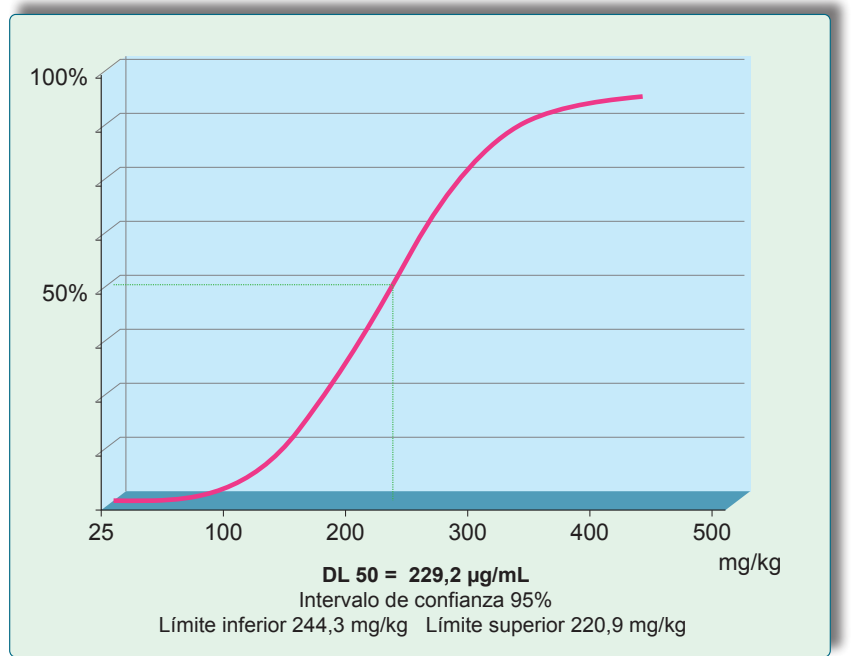

Figura 1. Curva de captación del radical superóxido producido por pirogalol de la vitamina C.

de agua y sus mediadores - endógenos y exógenos -, la sintomatología consecuente a nivel de la motilidad intestinal, y reducir los síntomas residuales; este efecto deseado se traduce en caracterizar las propiedades antidiarreicas del recurso fitoterapéutico Annona muricata L. ${ }^{(8)}$.

La guanábana (Annona muricata L.) pertenece a la familia Anonaceae, cuyas especies se caracterizan por ser plantas leñosas de hojas enteras, sin estípulas; del árbol maduro brotan hojas perennes. La zona de mayor producción incluye el Caribe, Centro y Sudamérica. Filogenéticamente es similar a la chirimoya, por su fruto de cáscara verde y sabor muy dulce, además se cultiva como ésta ${ }^{(6)}$. Todas las partes del árbol se han utilizado en la medicina tradicional y se le han atribuido diferentes propiedades contra diabetes, fiebre, hipertensión, indigestión, procesos inflamatorios, desórdenes hepáticos, parasitosis, tumores, úlceras, insomnio y diarrea ${ }^{(9)}$.

En los últimos años, el extracto de hojas de guanábana ha llegado a ser popular debido a sus propiedades contra el cáncer. Componentes secundarios, como las acetogeninas, están presentes en el tejido leñoso de las anonáceas y son sustancias cerosas que resultan de la combinación de ácidos grasos de cadena larga $\left(\mathrm{C}_{32}\right.$ ó C34) con una unidad de 2-propanol en el carbono 2 para formar una lactona terminal (dicha lactona queda al inicio de la cadena) ${ }^{(10)}$.

Se ha reportado que las acetogeninas pueden inhibir selectivamente el crecimiento de células cancerígenas resistentes a la adriamicina, precursor del antineoplásico doxorubicina ${ }^{(10,11)}$.

Estudios en el Caribe sugieren una relación entre el consumo de esta fruta y formas atípicas de la enfermedad de Parkinson, debido a la concentración muy alta de
Tabla 1. Identificación fitoquímica de Annona Muricata L.

\begin{tabular}{llc}
\hline \multicolumn{1}{c}{ Prueba } & \multicolumn{1}{c}{ Identificación } & Resultado \\
\hline Gelatina & Taninos & $(++)$ \\
Nihidrina & Aminoácidos libres & $(-)$ \\
Tricloruro de hierro & Compuestos fenólicos & $(++)$ \\
Draggendorf & Alcaloides & $(+)$ \\
Mayer & Alcaloides & $(+)$ \\
Hidróxido de sodio & Quinonas & $(-)$ \\
Alfa-naftol (Molish) & Glicósidos & $(+)$ \\
Shinoda & Flavonoides & $(++)$ \\
Lieberman & Terpenos & $(+)$ \\
Espuma & $(-)$ & $(-)$ \\
\hline$(-)$ negativo, $(+)$ poca cantidad, $(++)$ regular cantidad, $(+++)$ abundante cantidad
\end{tabular}

Tabla 2. Determinación de la dosis letal 50 del extracto metanólico de las hojas de Annona muricata L. sobre ratones (n=6).

\begin{tabular}{ccc}
\hline Grupos & $\begin{array}{c}\text { Tratamiento } \\
\text { (mg/kg) }\end{array}$ & $\begin{array}{c}\text { No de ratones } \\
\text { muertos }\end{array}$ \\
\hline 1 & 1000 & 6 \\
2 & 250 & 5 \\
3 & 235 & 3 \\
4 & 225 & 2 \\
5 & 210 & 1 \\
6 & 200 & 0 \\
7 & 100 & 0 \\
8 & 75 & 0 \\
9 & 50 & 0 \\
10 & 25 & 0 \\
11 & 10 & 0 \\
\hline
\end{tabular}

Tabla 3. Efecto del extracto metanólico de hojas de Annona muricata L. y loperamida sobre el tránsito gastrointestinal del carbón activado en ratones $(\mathrm{n}=6)$.

\begin{tabular}{ccccc}
\hline Tratamiento & Dosis & $\begin{array}{c}\text { Longitud } \\
\text { intestinal } \\
\text { media (cm) }\end{array}$ & $\begin{array}{c}\text { Media del } \\
\text { avance de } \\
\text { C.A. (cm) }\end{array}$ & $\begin{array}{c}\text { \% inhibición } \\
\text { del transito }\end{array}$ \\
\hline S. F. & $10 \mathrm{~mL} / \mathrm{kg}$ & 62,7 & 51,7 & 0,00 \\
A.M. & $10 \mathrm{mg} / \mathrm{kg}$ & 64,2 & 52,5 & 0,48 \\
A.M. & $25 \mathrm{mg} / \mathrm{kg}$ & 53,8 & 38,2 & 13,94 \\
A.M. & $50 \mathrm{mg} / \mathrm{kg}$ & 60,8 & 35,7 & 27,01 \\
A.M. & $75 \mathrm{mg} / \mathrm{kg}$ & 55,9 & 34,5 & 25,74 \\
A.M. & $100 \mathrm{mg} / \mathrm{kg}$ & 59,7 & 29,8 & 38,37 \\
A.M. & $200 \mathrm{mg} / \mathrm{kg}$ & 59,1 & 35,6 & 25,28 \\
Loperamida & $1 \mathrm{mg} / \mathrm{kg}$ & 56,5 & 39,9 & 13,36 \\
Aceite ricino & $10 \mathrm{~mL} / \mathrm{kg}$ & 61,4 & 49,5 & 1,53 \\
\hline
\end{tabular}

C.A. carbón activado, S.F. suero fisiológico, A.M. Annona muricata. Nivel de significancia: $p<0.05$

annonacina $(15 \mathrm{mg} / \mathrm{Kg})^{(12)}$, que es cien veces mayor que en el té elaborado a partir de sus hojas (140 $\mu \mathrm{g} /$ taza $)^{(13)}$.

El objetivo de la presente investigación fue determinar el efecto inhibitorio sobre el tránsito intestinal del extracto metanólico de las hojas de Annona muricata L. en ratones.

\section{MATERIALES Y MÉTODOS}

\section{Recolección de las hojas y obtención del extracto}

Las hojas de Annona muricata L. fueron colectadas en San José, distrito de Santiago de Cao, Provincia de Ascope, 
Región La Libertad; lavadas y secadas en una estufa a $38^{\circ} \mathrm{C}$ con aire circulante en el laboratorio de Farmacología de la Facultad de Medicina de la Univerisad Nacional Mayor de San Marcos (UNMSM). El material seco fue pulverizado en un molino de cuchillas. El extracto metanólico de las hojas se preparó según la técnica del CYTED $1995^{(21)}$; se maceró con metanol durante ocho días a temperatura ambiente con movimientos diarios. Se filtró y desecó a $38^{\circ} \mathrm{C}$, en estufa hasta peso constante. El residuo seco se conservó en frasco color ámbar a $4{ }^{\circ} \mathrm{C}$ hasta su uso. Para la administración se resuspendió utilizando un agente tensoactivo, aceite de castor hidrogenado (CremoforR $40 \mathrm{OS}$ al 5\%).

\section{Estudio fitoquímico preliminar}

En el extracto de las hojas de Annona muricata L. se evaluó la presencia de flavonoides, taninos, alcaloides, saponinas, glucósidos, y esteroles/tri-terpenos; usando los métodos de Odebiyi y Sofowora (1978) ${ }^{(22)}$.

\section{Diseño experimental}

Seutilizaron 120 ratones machosb $($ Balb-C 56$)$ de $24 \pm 2$ $\mathrm{g}$ de peso corporal procedentes del bioterio del Instituto Nacional de Salud (Chorrillos). Se les acondicionó por seis días en un ambiente de experimentación a $23^{\circ} \mathrm{C}$, con agua ad libitum y alimento balanceado estándar de ratón en pellet. Las consideraciones éticas se hicieron de acuerdo a los lineamientos del Departamento de Farmacología de la UNMSM y aspectos éticos de la experimentación con animales ${ }^{(23)}$.

\section{a. Toxicidad aguda}

Para LD5o se usó el método descrito por Lorke, 1983, con una modificación en el número de animales. Se utilizaron ratones Balb-C 56, divididos en grupos de seis al azar, en total se hicieron once grupos.

El extracto reconstituido fue administrado a cada grupo por vía oral a dosis de: 1000, 250, 235, 225, 210, 200, 100, 75 , 50, 10 y $2 \mathrm{mg} / \mathrm{kg}$ de peso corporal, respectivamente, registrándose la muerte de los animales desde las 24 horas y durante 14 días.

\section{b. Efecto en el tránsito intestinal}

Se formaron al azar nueve grupos de seis ratones cada uno, los cuales no recibieron alimento 12 horas antes de la experiencia, pero se les permitió tomar agua ad libitum. Al grupo control se le administró suero fisiológico vía oral, $10 \mathrm{mg} / \mathrm{kg}$ de peso corporal; a los grupos del 2 al 7 se les administró extracto metanólico a dosis de 10, 25, 50, 75, 100 y $200 \mathrm{mg} / \mathrm{kg}$ de peso corporal, respectivamente; el grupo 8 recibió $0,2 \mathrm{~mL}$ de solución de loperamida $0,04 \mathrm{mg} / \mathrm{mL}$ y el grupo 9 recibió aceite de ricino o,2 mL mediante una cánula metálica. Una hora después se administró por vía oral o,2 mL de suspensión de carbón activado en goma tragacanto $10 \mathrm{mg} / \mathrm{mL}$ como marcador. Una hora después de administrar el carbón activado, cada ratón fue sacrificado utilizando éter dentro de una campana extractora de gases; se diseccionó el abdómen y se procedió a eviscerar el

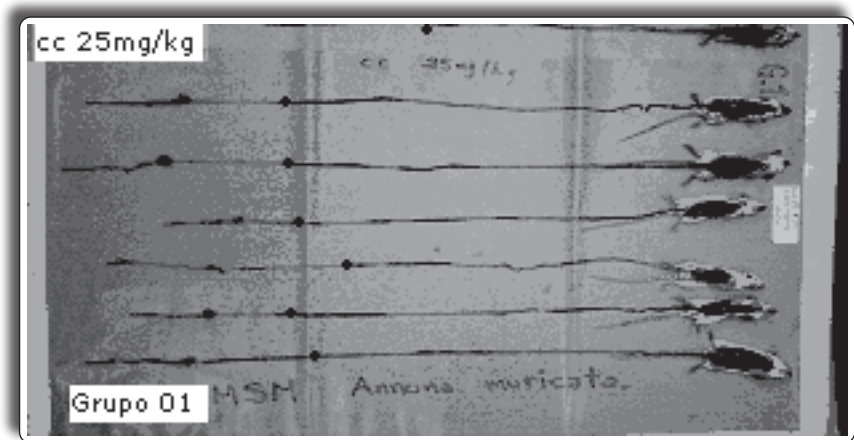

Figura 2. Gráfica del efecto del extracto metanólico de las hojas de Annona muricata $\mathrm{L}$. a dosis de $25 \mathrm{mg} / \mathrm{kg}$ sobre el tránsito intestinal del carbón activado en ratones.

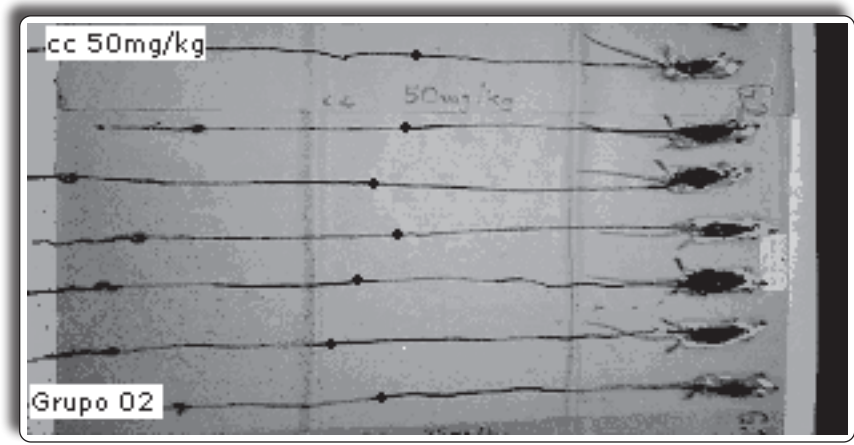

Figura 3. Gráfica del efecto del extracto metanólico de las hojas de Annona muricata L. a dosis de $25 \mathrm{mg} / \mathrm{kg}$ sobre el tránsito intestinal del carbón activado en ratones.

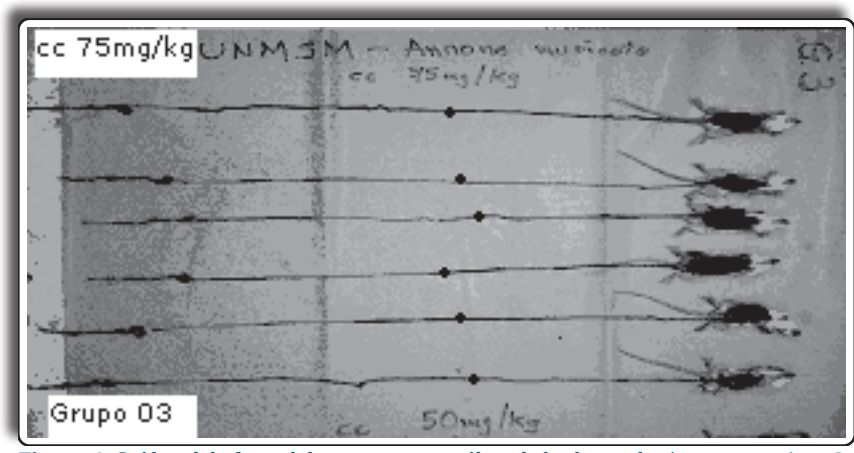

Figura 4. Gráfica del efecto del extracto metanólico de las hojas de Annona muricata L. a dosis de $75 \mathrm{mg} / \mathrm{kg}$

intestino, empezando por el borde del cardias hasta el ano para luego registrar las medidas tanto de la longitud total del intestino, así como del avance del carbón activado. Los porcentajes de inhibición de tránsito del carbón activado por la loperamida y por el extracto fueron calculados en función del grupo tratado con suero fisiológico (control negativo) usando la siguiente fórmula:

\section{\% Inhibición $=(\mathbf{N}-\mathbf{n}) / \mathbf{N} \times 100$}

Donde:

$\mathrm{N}$ : media del avance del carbón activado en el grupo control (suero fisiológico).

$\mathrm{n}$ : diferencia entre $\mathrm{N}$ y el avance del carbón activado en el grupo con tratamiento. 


\section{Análisis estadístico}

\section{Variables}

Toxicidad aguda: Se analizó por el método de Probits.

Tránsito intestinal: Se refiere a la distancia recorrida por la sustancia marcadora (carbón), siendo el 100\% del recorrido la longitud del tubo digestivo que abarca desde el cardias hasta el ano. Se utilizaron promedios \pm error estándar, porcentaje y análisis de varianza utilizando $\mathrm{p}<\mathrm{0}, 05$ para valores estadísticamente significativos.

\section{RESULTADOS}

\section{Estudio fitoquímico}

El extracto metanólico de las hojas de Annona muricata L. está constituido principalmente por taninos, compuestos fenólicos, flavonoides, alcaloides, glucósidos y terpenos (Tabla 1 ).

\section{Estudios de seguridad: determinación de la dosis letal 50 en ratones}

La dosis letal 50 para el extracto metanólico de las hojas de Annona muricata L. determinada en ratones y administrada por vía oral fue de $229,2 \mathrm{mg} / \mathrm{kg}$ con un intervalo de confianza al 95\%, siendo el límite inferior 220,9 $\mathrm{mg} / \mathrm{kg}$ y el superior de $244,3 \mathrm{mg} / \mathrm{kg}$ (figura 1 y tabla 2 ).

\section{Efecto sobre el tránsito intestinal}

Los resultados del efecto sobre el tránsito intestinal son mostrados en la tabla 3, donde se observa que el efecto provocado por el extracto metanólico de las hojas de Annona muricata L. administrado vía oral a dosis de 25 $\mathrm{mg} / \mathrm{kg}$ es semejante al dado por la loperamida a $1 \mathrm{mg} / \mathrm{kg}$; mientras que con las dosis de 50, 75, 100 y $200 \mathrm{mg} / \mathrm{Kg}$ de peso corporal, se redujo el tránsito significativamente $(\mathrm{p}<$ o,05) al ser comparados con el grupo control.

\section{DISCUSIÓN}

La disminución del tránsito intestinal en ratones es un modelo farmacológico preclínico, que permite sustentar la hipótesis de que el extracto metanólico de las hojas de Annona muricata L. tiene acción antidiarreica; asimismo, el efecto obtenido comparado con la loperamida (14) refuerza el resultado encontrado con el extracto metanólico, el cual disminuyó el tránsito intestinal del carbón activado administrado como marcador en ratones (tabla 3).

Los resultados (figura 2 y tabla 3 ) muestran el mayor efecto sobre el tránsito intestinal a dosis de $100 \mathrm{mg} / \mathrm{kg}$ $(38,37 \%)$, mientras que a dosis de $25 \mathrm{mg} / \mathrm{kg}(13,94 \%)$ el efecto fue semejante al de loperamida a $1 \mathrm{mg} / \mathrm{kg}(13,36 \%)$.

Cabe precisar que si bien a dosis de $100 \mathrm{mg} / \mathrm{kg}$ de extracto se produce el mayor efecto antidiarreico, no lo sugerimos porque según los estándares farmacológicos no necesitamos llegar a utilizar dicha dosis.
Estos resultados también demostraron que el efecto antidiarreico no depende de la concentración del extracto, por cuanto a dosis mayores de $100 \mathrm{mg} / \mathrm{kg}$ el efecto sobre la motilidad intestinal disminuye.

El efecto global de inhibición del peristaltismo anormal que ejerce el extracto de las hojas de Annona Muricata L. puede atribuirse a los compuestos fenólicos (taninos, flavonoides) con actividad antidiarreica, ya que existe información que indica la presencia de taninos en diversas variedades de plantas empleadas en el tratamiento de diarreas ${ }^{(15-17)}$.

Similar resultado obtuvieron Suleiman M, Dzenda T, Sani C, cuando compararon el efecto antidiarréico en ratones de Annona senegalensis con loperamida, que fue usada como control positivo ${ }^{(2)}$. La loperamida es un fármaco antidiarreico activo por vía oral, con actividad sobre el receptor $\mu$, que disminuye la secreción y motilidad gástrica ${ }^{(18)}$.

Como se sabe, el aumento de las contracciones y el peristaltismo son producidos por la actividad colinérgica ${ }^{(19)}$, por lo que podemos deducir que uno de los probables mecanismos por el cual, el extracto de las hojas de Annona muricata L., ejerce su acción antidiarreica es actuando como un antagonista de la actividad colinérgica.

\section{CONCLUSIONES}

En condiciones experimentales, el extracto metanólico de las hojas de Annona muricata L. a dosis de $25 \mathrm{mg} / \mathrm{kg}$ demostró una marcada disminución del tránsito intestinal.

En el contexto de un enfoque toxicológico, se determinó que la dosis letal $50\left(\mathrm{DL}_{50}\right)$ del extracto metanólico de las hojas de Annona muricata L., administrado por vía oral en ratones normales, es de 229 $\mathrm{mg} / \mathrm{Kg}$.

\section{REFERENCIAS BIBLIOGRÁFICAS}

1. Riverón R. Fisiopatología de la diarrea aguda. Rev. Cubana de Pediatría 1999; 71: 96-115.

2. Ossa G. Diarrea Aguda - Aspectos Patológicos y Epidemiológicos. Sociedad de Gastroenterología de Santiago de Chile 2005; 1 : 3.

3. Suleiman M, Yusuf S. Antidiarrheal Activity of the Fruits of Vitex doniana in Laboratory Animals. Pharmaceutical Biology 2008; 46 (6): 387-92.

4. Morón F, Martínez M, Morón D. Disminución del tránsito intestinal en ratones por tintura de guayaba (Psidium guajava L.) oral. Rev Cubana Plant Med 1999; 4(2): 54-6.

5. Román E, Barrio J. Diarrea aguda. Protocolos de Gastroenterología, Hepatología y Nutrición. Protocolos de la AEP. 2002. [En línea] Citado el 14 de diciembre 2008. Disponible en http://www.aeped.es/protocolos/gastroentero/2.pdf

6. Guerrant L, Hughes J, Lima N, Grane J. Diarrea in Developed and developing countries: magnitude, special setting and etiologies. Rev Infect Dis 1990; 12 Suppl 1: 41-50

7. Croci T, Landi M, Le Fur G, Manara L. Role of tachykinins in 
castor oil diarrhoea in rats. British Journal of Pharmacology 1977; 121(3): 375-80.

8. Márquez C, Caracterización Fisiológica, Físico-Química, Reológica, Nutraceútica, Estructural y Sensorial de la Guanábana (Annona muricata L.). Universidad Nacional de Colombia. 2009. [En línea] Citado el 20 de diciembre 2008. Disponible en http://www.bdigital.unal.edu. co/1824/1/8740420.2009.pdf

9. Feras Q, et al. 1999. "Annonaceous acetogenins: Recent progress." J Nat Prod 62(3): 504-40.

10. Stephen J, Horace G. Cutler. Thwarting resistance: annonaceous acetogenins as new pesticidal and antitumor agents. En Biologically Active Natural Products: Pharmaceuticals. CRC Press 200o; 4: 84-87.

11. Schlie M, Gonzáles A, Luna L. Las acetogeninas de annonaceae: Efecto antiproliferativo en líneas celulares neoplásicas. Boletín Latinoamericano y del Caribe de Plantas Medicinales y Aromáticas 2009; 8: 245-57.

12. Lannuzel A. The mitochondrial complex I Inhibitor annonacin is toxic to mesencephalic dopaminergic neurons by impairment of energy metabolism. Neuroscience 2003; 121: 287-96.

13. Champy P, Melot A, Guérineau V, Gleye C, Fall D. Quantification of acetogenins in Annona muricata linked to atypical parkinsonism in Guadeloupe. Movement Disorders 2005; 20: 1629-33.

14. Hughes S, Higgs N, Turnberg L. Antidiarrhoeal activity of loperamide: Studies of its influence on ion transport across rabbit ileal mucosa in vitro. Gut 1982; 23: 974-79. [En línea] Cita el 20 de Setiembre de 2009. Disponible en http://www.gut. bmj.com

15. Sagar L, Sehgal R, Ojha S. Evaluation of antimotility effect of Lantana camara L. var. acuelata constituents on neostigmine induced gastrointestinal transit in mice. BMC Complementary and Alternative Medicine 2005; 5: 18-19.
16. Bouquet A, Debray M. Plantes Médicinales de la Côte d'Ivoire. Travaux et Documents $\mathrm{N}^{\circ}$ 32. French Scientific Research Institute for Development Cooperation. Paris, 1974. p 231.

17. Kerharo J, Adam J. Phamacopee Senegalaise Tradionnelle. Plantes Medicinales et Toxiques. Vigot-Freres. Paris 1974. p 1016-21.

18. Brunton L, Lazo, Parker, K. Goodman \& Gilman's the pharmacological basis of therapeutics. $11^{\mathrm{a}}$ Ed. McGraw-Hill Interamericana. México, 2005. p 350-6.

19. Guyton \& Hall, Tratado de Fisiología Médica, $11^{\mathrm{a}}$ Ed. Elsevier. Madrid, 2006. p 787-90.

20. McNeill P. The Ethics and Politics of Human Experimentation. Cambridge University Press. Cambridge, 1993. p 115-8.

21. CYTED. Manual de técnicas de investigación. Madrid 1995.

22. Odebiyi, A, Sofowora E. Phytochemical screening of Nigerian medicinal plants Part II. Lloydia 1978: 228-46.

23. González D. Modelos animales de dolor y aspectos éticos de la experimentación animal. Rev Soc Esp Dolor 2000; $7(5): 313-318$

Manuscrito recibido el: 26/11/2009

Aceptado para su publicación el: 14/04/2011

\section{Correspondencia:}

Nombres: Dorka Salinas Aramburú / Jorge Luís Arroyo Acevedo

Dirección: Jr. Puno 1002 - Lima o1 - Perú

e-mail: dorisasal@hotmail.com / jorgeluis_arroyoacevedo@yahoo.es 